diameter, smoking status and HLA-B27. There was predominance of male (81\%), Caucasoid (75\%), non-smoking (64\%) and positive HLA-B27 (75\%) patients, with dorsal spine involvement in $58 \%$. Mean age was 40 years and mean disease duration was 16 years.

Results There were five patients $(10 \%)$ with an altered plain chest radiography. PFT presented a restrictive pattern in 52\% of the patients. Thoracic HRCT showed abnormalities in 21 patients $(40 \%)$, predominantly nonspecific linear parenchymal opacities (19\%), lymphadenopathy (12\%), emphysema (10\%), bronquiectasis $(8 \%)$ and pleural involvement $(8 \%)$. Male sex was statistically associated with dorsal involvement $(\mathrm{p}=0.012)$. Non-Caucasoid race was associated with bronquiectasis ( $\mathrm{p}=$ $0.044)$ and pleural involvement $(p=0.044)$ at the thoracic HRCT. Smoking patients presented more linear parenchymal opacities $(p=0.026)$ at the thoracic HRCT. Negative HLA-B27 was associated with an altered plain chest radiography $(\mathrm{p}=$ 0.011). Dorsal spine involvement was associated with restrictive pattern at PFT $(\mathrm{p}=0.001)$ and linear parenchymal opacities $(\mathrm{p}$ $=0.032$ ) at the thoracic HRCT. A lower thoracic diameter was observed in patients with dorsal spine involvement $(\mathrm{p}=$ $0.0001)$, restrictive pattern at PFT $(\mathrm{p}=0.023)$ and linear parenchymal opacities $(\mathrm{p}=0.015)$ at the thoracic HRCT.

Conclusion Subclinical pulmonary involvement is frequent in AS. The restrictive pattern at PFT is associated with dorsal spine involvement and a low thoracic diameter, whilst the thoracic HRCT presents a series of nonspecific alterations, predominating the linear parenchymal opacities.

\section{SAT0019 COMPARISON OF DIFFERENT IMAGING TECHNIQUES IN THE DIAGNOSIS OF SPONDYLARTHROPATHIES}

${ }^{1} \mathrm{~N}$ Arýtan, ${ }^{1} \mathrm{P}$ Atagündüz, ${ }^{2} \mathrm{~T}$ Biren, ${ }^{3} \mathrm{HT}$ Turoðlu, ${ }^{1} \mathrm{H}$ Direskeneli. ${ }^{1}$ Rheumatology; ${ }^{2}$ Radiology; ${ }^{3}$ Nuclear Medicine, University of Marmara, Faculty of Medicine, Istanbul, Turkey

\subsection{6/annrheumdis-2001.371}

Background Diagnosis of radiological sacroiliitis is difficult in the early stages with plain radiographs. Advanced methods such as computed tomography (CT), scintigraphy and magnetic resonance imaging (MRI) are suggested for this purpose.

Objectives To compare the role of different imaging techniques in the diagnosis of spondylarthropathy $(\mathrm{SpA})$ patients with inflammatory low back pain.

Methods Thirty-four sacroiliac joints in 17 SpA patients who fulfilled the 1984 European Spondylarthropathy Classification Criteria and had inflammatory low back pain were investigated. Plain radiography, quantitative scintigraphy and MRI were performed for sacroiliac imaging. Plain radiography findings were evaluated blindly by a radiologist and rated on a $0-5$ scale according to the modified New York criteria for radiological sacroiliitis. Quantitative sacroiliac scintigraphy was performed with Tc-99m hydroxy methylene diphosphonate (HMDP) and sacroiliac joint/sacrum uptake ratio for each joint was its sacroiliac index (SII). The value of SII >136 was considered as sacroiliitis. The patients also underwent MRI of sacroiliac joints with FSE T2 and SE T1 weighed images.

Results Among SpA patients the sensitivity of scintigraphy, MRI and plain radiography was $79 \%, 59 \%$ and $32 \%$ respectively. In $32 \%$ of 34 sacroiliac joints in which sacroiliitis was demonstrated with scintigraphy, no pathologic changes were present with MRI. On the other hand, $6 \%$ of joints were positive with MRI, but negative with scintigraphy. In cases where plain radiography showed normal radiographs, scintigraphy showed abnormalities in 44\% while MRI showed abnormalities in only $18 \%$ of the joints. We couldn't find any relationship between the sacroiliac index and plain radiography scores.

Conclusion These results suggest that the sensitivity of scintigraphy was higher than plain radiography and MRI, especially in early sacroiliitis patients with SpA.

\section{SAT0020 SERUM NITRIC OXIDE, CATALASE, SUPEROXIDE DISMUTASE, XANTINE OXIDASE AND MALANDIALDEHYDE STATUS IN PATIENTS WITH ANKYLOSING SPONDYLITIS}

'S Ozgocmen, 'O Ardicoglu, ${ }^{2} \mathrm{~S}$ Sogut, ${ }^{1}$ I Pekkutucu, ${ }^{3} \mathrm{E}$ Fadillioglu, ${ }^{2} \mathrm{O}$ Akyol. 'Physical Medicine and Rehabilitation, Firat University, Faculty of Medicine, Elazig; ${ }^{2}$ Biochemistry; ${ }^{3}$ Physiology, Inonu University, Faculty of Medicine, Malatya, Turkey

10.1136/annrheumdis-2001.372

\section{Background}

Objectives In this study serum antioxidant and oxygen derived free radical status of patients with ankylosing spondylitis (AS) has been investigated and compared with age and sex matched healthy controls.

Methods Thirty patients fulfilling the New York criteria for AS and age and sex matched 16 healthy control subjects were included in the study. Patients who were smoking, under the treatment of DMARDs or any other drugs (except NSAIDs informally used by the patients) excluded.

Catalase (CAT) (EC 1.11.1.6) activity was measured by the determination of rate constant of hydrogen peroxide decomposition. Total $(\mathrm{Cu}-\mathrm{Zn}$ and $\mathrm{Mn})$ SOD (EC 1.15.1.1) activity was determined by the method based on the inhibition of NBT reduction by the xanthine-xanthine oxidase system. Malandialdehyde (MDA) levels determination was based on the coupling of MDA with thiobarbituric acid (TBA) at $+95 \stackrel{\circ}{\circ}$. XO (EC 1.2.3.2) activity was measured spectrophotometrically by the formation of uric acid from xanthine through the increase in absorbency at $293 \mathrm{~nm}$. Nitrite (NO2-) and nitrate (NO3-) were estimated as an index of NO production. Quantitation of nitrate and nitrite was based on the Griess reaction, in which a chromophore with a strong absorbency at $540 \mathrm{~nm}$ is formed by reaction of nitrite with a mixture of naphthlethylenediamine and sulphanilamide.

Results Patients had significantly higher MDA and CAT activity with respect to controls. CAT activity of patients correlated significantly with CRP and ESR levels.

Conclusion Our results indicate that MDA and CAT activity increase in patients with AS, and CAT activity may be related to disease activity.

\section{SAT0021 THE INCIDENCE OF VARICOCELES IN PATIENTS WITH ANKYLOSING SPONDYLTIS EVALUATED BY PHYSICAL EXAMINATION AND COLOUR DOPPLER SONOGRAPHY}

${ }^{1} \mathrm{~S}$ Ozgocmen, ${ }^{2} \mathrm{E}$ Kocakoc, ${ }^{2} \mathrm{~A}$ Kiris, ${ }^{3} \mathrm{~A}$ Ardicoglu, ${ }^{1} \mathrm{O}$ Ardicoglu. ${ }^{1}$ Physical Medicine and Rehabilitation; ${ }^{2}$ Radiology; ${ }^{3}$ Urology, Firat University, Faculty of Medicine, Elazig, Turkey

\subsection{6/annrheumdis-2001.373}

Background A varicocele is an abnormal tortuosity and dilation of the testicular veins within the spermatic cord. The incidence of varicocele in AS, which affects predominantly young male individuals, is unknown. 